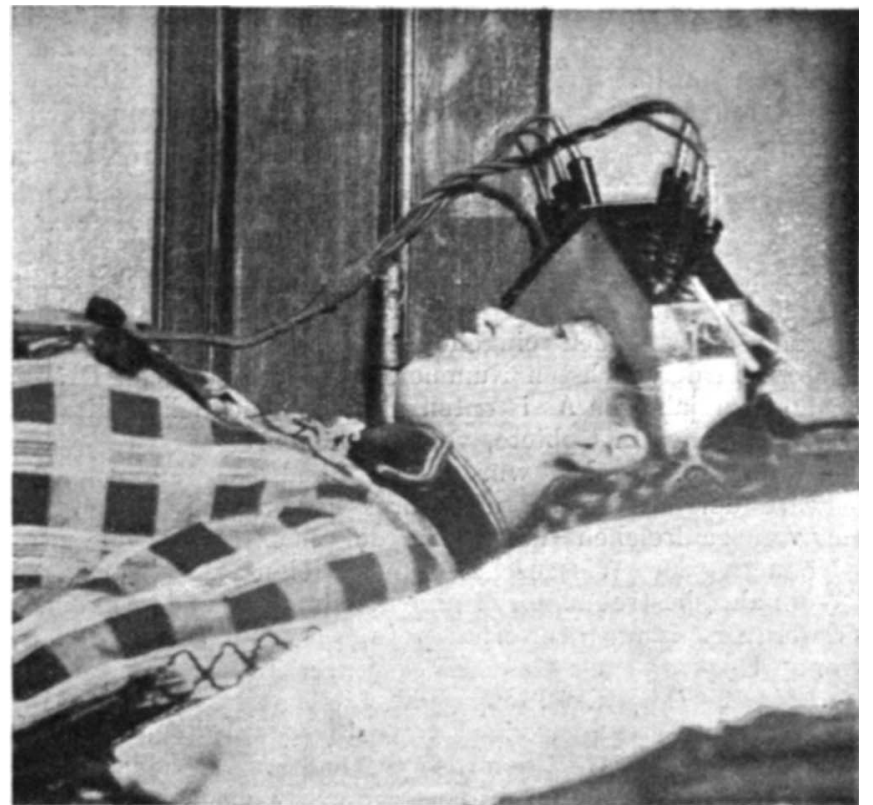

(Die Firma Reiniger, Gebbert und Schall in Erlangen fabriziert die „Neptunkappe“.)

\title{
Korrespondenzen.
}

\section{Zur Behandlung der Seekrankheit.}

Von Paul Kappmeier, Landschafts- und Marinemaler in Altkloster (Kreis Stade).

In dieser Wochenschrift No. 3, S. 110, hat Herr Eugen Wolf in seinem Aufsatze, Für Seekranke ${ }^{\text {s }}$ auch die von mir zur Behandlung der Seekrankheit konstruierte „Neptunkappe“ erwähnt. Seiner Beschreibung möchte ich noch nachfolgende genauere Einzelheiten hinzufügen:

Ein Filzbelag, der sich bequem um Stirn und Schläfen legen läbt, wird mittels einer Lederkappe und einer feststellbaren Spannyorrichtung so fest um den Schảdel gelegt, daß dazwischen gerade noch die Zirkulation möglich ist. Die Filzkompresse wird vor der Benutzung in Wasser getaucht und dann anf dem Kopfe durch elektrische Beheizungskörper andauernd heiß erhalten. Letztere, die gleichfalls mit der die ganze Kappe fixierenden Spannvorrichtung verbunden sind, werden von der am Bord befindlichen elektrischen Stromanlage gespeist. Mit dieser Kopfkompresse wird die Beseitigung der Hirnanämie, der Ursache der Seekrankheit, ebenso sicher wie einfach erzielt. Sie hat den Vorteil, daß sich der Patient während der Anwendung vollkommen ruhig verhalten kann, da ein Wechsel der "Neptunkappe" nicht nötig ist. Diese ist mit aseptischer Einlage versehen, sodab einer allgemeinen $\mathrm{Be}$ nutzung nichts im Wege steht; auch ist sie so kompendiös konstruiert, daß jeder seine eigene Kappe mit sich führen kann. Meine Beobachtungen haben mir stets giinstige Resultate ergeben, und wird es nur eine kurze Zeitfrage sein, den Apparat in umfangreichstem Gebrauch zu sehen. 